\title{
Assessment of Lipid Profile and Atherogenic Indexes of Hepatitis B Virus Carriers amongst Volunteer Blood Donors in Nigeria
}

\author{
Kingsley Kalawari Odiabara1, Edna Ogechi Nwachuku1, Ndokiari Boisa², \\ Ebirien-Agana Samuel Bartimaeus ${ }^{{ }^{*}}$ \\ ${ }^{1}$ Department of Medical Laboratory Science, Rivers State University, Nkpolu-Oroworukwo, Port Harcourt, Nigeria \\ ${ }^{2}$ Department of Chemistry, Rivers State University, Nkpolu-Oroworukwo, Port Harcourt, Nigeria \\ Email: ^ebbyagana@gmail.com
}

How to cite this paper: Odiabara, K.K., Nwachuku, E.O., Boisa, N. and Bartimaeus, E.-A.S. (2020) Assessment of Lipid Profile and Atherogenic Indexes of Hepatitis B Virus Carriers amongst Volunteer Blood Donors in Nigeria. Journal of Biosciences and Medicines, 8, 81-95.

https://doi.org/10.4236/jbm.2020.84007

Received: February 21, 2020

Accepted: April 12, 2020

Published: April 15, 2020

Copyright $\odot 2020$ by author(s) and Scientific Research Publishing Inc. This work is licensed under the Creative Commons Attribution International License (CC BY 4.0).

http://creativecommons.org/licenses/by/4.0/

(c) (i) Open Access

\begin{abstract}
Introduction: Infectious agents such as hepatitis B virus can constitute major public health problems as ii affects the liver resulting into inflammatory conditions. This study was designed to assess plasma lipid profile and atherogenic indexes of hepatitis B virus carriers among voluntary blood donors in North Central, North East and South-South regions of Nigeria. Materials \& Methods: A total of 183 blood samples were collected from subjects in North Central consisting of 137 males and 46 females; 176 blood samples from the North East consisting of 129 males and 47 females and 173 blood samples from subjects in South-South region consisting of 123 males and 50 females. The mean ages of the subjects were $34.89 \pm 9.19$ years, $39.81 \pm 9.60$ years and $39.92 \pm 9.27$ years for North Central, North East and South-South regions respectively. The specimens were tested for hepatitis $B$ surface antigen using enzyme-linked immunosorbent assay. All specimens were analyzed for total cholesterol, HDL-C, LDL-C and triglycerides with standard biochemical procedures. The atherogenic indexes were computed using established ratios. The data was analyzed statistically and p-value $<0.05$ was considered significant. Results: The mean values of total cholesterol, high density lipoprotein cholesterol, low density lipoprotein cholesterol, and triglycerides did not vary significantly $(p>0.05)$ between the hepatitis B positive carriers and hepatitis $B$ negative subjects across the geo-political zones studied although in some of the parameters the values were on the high normal range between the male and female subjects. The AIP and CRR-1 and CRR-11 of the blood donors in the zones in both the HBsAg positive and negative subjects were within the reference range. The atherogenic coefficient value of $>3.0$ was obtained for some HBsAg negative and positive subjects in some of the zones. Conclu-
\end{abstract}


sion: The findings thus indicate that asymptomatic HBV infection may be associated with low risk of dyslipidaemia in the population.

\section{Keywords}

Hepatitis, Atherogenic Indices, Lipoproteins, Cardiovascular Disease, Blood Donors

\section{Introduction}

Transfusion of blood and blood products as a specialized modality of patient management has been saving many lives. It is well known that there are complications that can occur due to blood transfusion. Some are only trivial and others are life-threatening, demanding for meticulous pretransfusion screening, and testing. The infection that could be transmitted by transfusion of unscreened blood includes Hepatitis B Virus (HBV) infection is a global public health problem. Hepatitis B Virus (HBV) infection is a global health menace with over 2 billion people living with the virus worldwide, and 257 million people suffering from the chronic stage infection [1]. WHO estimated that about 1.34 million HBV infected patients in 2015 died due to chronic hepatitis, cirrhosis, and hepatocellular carcinoma, and other liver-related complications, and the infection has been found to cause epidemics in most parts of Asia and tropical African countries [1].

The reduction of public health burden is the goal of many intervention strategies in the health sectors of countries. Several infectious agents such as Hepatitis B Virus (HBV) can constitute major public health problems [2] [3]. Similarly, in Sub-Saharan Africa and other developing countries of the world, Hepatitis B is a viral infection which causes acute and chronic hepatitis leading to thousands of deaths per year and it is considered one of the major public health issues worldwide. It affects the liver resulting in inflammatory conditions [4]. Although majority of individuals recover from the acute infection, those who progress to chronic hepatitis B infection are at greater risk of developing serious complications such as cirrhosis, hepatocellular carcinoma, liver failure and eventual death [5].

The liver is the main target of hepatitis B infection which could be acute or chronic [4]. Acute hepatitis involves sudden injury on the hepatocytes and is of short duration, usually less than six months, while chronic hepatitis is characterized by persistent inflammatory damage to hepatocytes and is of a longer duration more than six months [6].

The clinical outcome in both acute and chronic hepatitis B infection is strongly dictated by age and immune status of the patient. However, about $30 \%$ to $50 \%$ of adolescents and adults develop jaundice [6]. Symptoms of acute hepatitis may include low grade fever, joint and muscle pain, loss of appetite and stomach pain. Some patients may present with more severe symptoms such as 
bloated stomach, jaundice, nausea and vomiting. Chronic hepatitis B infected individuals are at risk of developing persistent liver inflammation including hepatocellular destruction leading to cirrhosis and hepatocelular carcinoma [7]. Symptoms of chronic HBV infection may not be obvious for months or years. However, commonly observed symptoms are dark urine, joint pain, loss of appetite, weakness, jaundice, anorexia, fatigue and rash.

Although, the effect of HBV on lipid profile and dyslipidaemia has been extensively studied on HBV patients and experimental models, the association between Hepatitis B Virus (HBV) and lipid metabolism in apparently healthy volunteer blood donors in Nigeria has been rarely reported. This study was, therefore, designed to assess the lipid profile and atherogenic indexes of HBV carriers among voluntary blood donors in three geo-political regions in Nigeria. The geopolitical zones are South-South, North Central and North East in Nigeria.

\section{Materials and Methods}

\subsection{Study Subjects}

The study subjects were prospective voluntary blood donors who had been certified fit to donate at the National Blood Transfusion Service after undergoing relevant medical checks and pre-donation counseling. They were aged between 18 years and 64 years. They weighed $50 \mathrm{~kg}$ and above. The exclusion criteria included haemoglobin concentration lower than $13.0 \mathrm{~g} / \mathrm{dL}$ in males and $12.5 \mathrm{~g} / \mathrm{dL}$ in females, blood pressure systolic $\geq 150 \mathrm{~mm} / \mathrm{Hg}$, Diastolic $\geq 100 \mathrm{~mm} / \mathrm{Hg}$; pulse $>100$ beats per minute; age $<18$ years; pregnant or nursing mothers; co-infection with human immunodeficiency virus (HIV), or hepatitis B virus (HCV).

\subsection{Sample Size Calculation}

The study was a cross sectional one. The sample size for the study was determined using the formula for cross sectional studies [8]. The study sample size required from each geopolitical zone was 150 subjects.

\subsection{Ethical Approval}

This study was approved by the National Health Research Ethics Committee. Approval was also obtained from the National Blood Transfusion Service in the three geopolitical zones for the use of their platforms to recruit voluntary blood donors for the study and informed consent was obtained from all the study participants.

\subsection{Collection of Blood Specimen and Testing}

Blood specimens were collected from the voluntary blood donors (after donating a unit of blood) into ethylene diamine tetra acetic acid (EDTA) specimen containers. After an overnight fast, blood specimens were collected again into lithium heparin containers from the subjects. EDTA specimen was centrifuged 
and the plasma used in determination of hepatitis B surface antigen (HbsAg) and viral load in $\mathrm{HBs} \mathrm{Ag}$ positive samples.

\subsection{Determination of Hepatitis B Surface Antigen (HbsAg)}

Enzyme linked immunosorbent assay technique (ELISA) using Monolisa HBsAg Ultra kit was used. The assay is a qualitative one-step enzyme immunoassay technique of sandwich type for the detection of HBsAg in human serum or plasma and it is intended for screening of blood during donation and for diagnostics [9].

\subsection{Determination of Hepatitis B Virus DNA (Viral Load)}

Hepatitis B virus DNA determination in human plasma was done the Cobas Ampliprep/CobasTaqMan HBV test version 2.0 which is a molecular assay designed for the quantification of HBV DNA [10]. The test is based on two major processes which include specimen preparation to isolate HBV DNA and simultaneous PCR amplification of target DNA and detection of cleaved dual-labeled oligonucleotide detected probe specific to the target. It is a real-time molecular assay which permits automated sample preparation, automated PCR amplification and detection of HBV Quantitation Standard (QS).

\subsection{Determination of Biochemical Parameters}

Serum lipid profile, including total cholesterol (Tchol), high density lipoprotein cholesterol (HDL-C) and triglycerides (TG) were determined using a Chemwell $^{(\mathrm{R})}$ T-Automated Chemistry Analyzer, produced by Awareness Technology Inc., USA. The ChemWell $-\mathrm{T}$ is a fully automated open system analyzer for biochemistry assays and is supplied with optimized programmed protocols ready for use with an extensive range of Megazyme test kits. All the reagents and serum samples were left out to adjust to room temperature prior to analyses Low density lipoprotein cholesterol (LDL-C) was calculated using the Friedewald et al. [11] equation.

\subsection{Calculation of Atherogenic Indexes}

The Atherogenic ratios were calculated as follows:

Atherogenic Index of Plasma (AIP) = log TG/HDL-C [12];

Cardiac Risk Ratio-1 (CRR-I) = TC/HD-C [13] [14];

Cardiac Risk Ratio-11 (CRI-II) = LDL-C/HDL-C [13] [14];

Atherogenic Coefficient $(\mathrm{AC})=(\mathrm{TC}-\mathrm{HDL}-\mathrm{C}) / \mathrm{HDL}-\mathrm{C}[15]$.

\subsection{Statistical Analysis}

The results were analyzed using Statistical Analysis System (SAS). STAT 15.1 developed by SAS Institute, North Carolina State University, USA. Data were presented as mean \pm SEM, comparison of means of groups that were more than two was done using one-way analysis of variance (ANOVA) and the Tukey test 
of multiple comparison was used to test for variance across groups. Variations in means of parameters were considered statistically significant at $\mathrm{p}<0.05$.

\section{Results}

\subsection{The Demographics of the Study Population}

A total of 532 voluntary unpaid blood donors participated in the study. The study population of voluntary blood donors in the North Central geo-political zone was 183 with a mean age of $34.89 \pm 9.19$ years out of which 154 (84.15\%) were negative to hepatitis B (HBsAg) and 29 (15.85\%) participants were HBsAg positive. Among the population of HBsAg negative in the zone, 113 were males with means age of $41.91 \pm 9.25$ years, while 41 were females with mean age of $35.29 \pm 9.52$ years. In the North East geopolitical zone, 176 voluntary blood donors with mean age $39.81 \pm 9.60$ years participated in the study. Hepatitis B (HBsAg) negative participants were $156(88.64 \%)$ made up of males 114 $(64.77 \%)$ with mean age of $44.12 \pm 7.35$ years and females $42(23.86 \%)$ with mean age of $28.05 \pm 6.10$ years while $20(11.36 \%)$ participants comprising of 15 (8.52\%) males with a mean age of $42.13 \pm 4.07$ years and 5 (2.84\%) females with a mean age of $33.40 \pm 2.61$ years. In the South-South geopolitical zone, 173 voluntary blood donors with mean age of $39.92 \pm 9.27$ years participated in the study. Hepatitis B (HBsAg) negative subjects were 153 (88.44\%) made up of males 109 (63.01\%) with mean age of $43.41 \pm 8.13$ years and females 44 (25.43\%) with mean age of $31.45 \pm 7.55$ years while 20 (11.56\%) participants comprising of $14(8.09 \%)$ males with a mean age of $42.00 \pm 3.59$ years and $6(3.47 \%)$ females with a mean age of $33.67 \pm 7.15$ years were $\mathrm{HBs} A g$ positive. Combining the three zones, the percentage prevalence of HBsAg negative by gender was $63.16 \%$ for males and $23.87 \%$ for the females while the prevalence of HBsAg positive by gender was $9.96 \%$ for the males and $3.01 \%$ for the females. However, the percentage prevalence of HBsAg negative irrespective of sex for the three zones combined was $87.03 \%$ while the percentage prevalence of $\mathrm{HBsAg}$ positive was $12.97 \%$ (Table 1).

Table 1. Sociodemographic characteristics of the study population.

\begin{tabular}{|c|c|c|c|c|c|c|c|c|c|}
\hline \multirow{4}{*}{ Characteristic } & \multirow{4}{*}{$\mathrm{N}(\%)$} & \multicolumn{8}{|c|}{ Treatment Groups } \\
\hline & & \multicolumn{4}{|c|}{ Hepatitis Negative } & \multicolumn{4}{|c|}{ Hepatitis Positive } \\
\hline & & \multicolumn{2}{|c|}{ Male } & \multicolumn{2}{|c|}{ Female } & \multicolumn{2}{|c|}{ Male } & \multicolumn{2}{|c|}{ Female } \\
\hline & & $\mathbf{N}$ & $\%$ & $\mathbf{N}$ & $\%$ & $\mathbf{N}$ & $\%$ & $\mathbf{N}$ & $\%$ \\
\hline North Central & $183(100)$ & 113 & 61.75 & 41 & 22.40 & 24 & 13.11 & 5 & 2.73 \\
\hline Age $($ Mean \pm SD) & $34.89 \pm 9.19$ & \multicolumn{2}{|c|}{$41.91 \pm 9.25$} & \multicolumn{2}{|c|}{$35.29 \pm 9.52$} & \multicolumn{2}{|c|}{$39.42 \pm 5.52$} & \multicolumn{2}{|c|}{$31.60 \pm 5.32$} \\
\hline North East & $176(100)$ & 114 & 64.77 & 42 & 23.86 & 15 & 8.52 & 5 & 2.84 \\
\hline Age $($ Mean \pm SD) & $39.81 \pm 9.60$ & \multicolumn{2}{|c|}{$44.12 \pm 7.35$} & \multicolumn{2}{|c|}{$28.05 \pm 6.10$} & \multicolumn{2}{|c|}{$42.13 \pm 4.07$} & \multicolumn{2}{|c|}{$33.40 \pm 2.61$} \\
\hline South-South & $173(100)$ & 109 & 63.01 & 44 & 25.43 & 14 & 8.09 & 6 & 3.47 \\
\hline Age $($ Mean $\pm S D)$ & $39.92 \pm 9.27$ & \multicolumn{2}{|c|}{$43.41 \pm 8.13$} & \multicolumn{2}{|c|}{$31.45 \pm 7.55$} & \multicolumn{2}{|c|}{$42.00 \pm 3.59$} & \multicolumn{2}{|c|}{$33.67 \pm 7.15$} \\
\hline
\end{tabular}


The viral load (VL) of HBsAg positive subjects disaggregated by geopolitical zone is shown in Table 2. The distribution shows that North Central zone has the highest viral load mean of $31.8439 \pm 12.784 \mathrm{IU} / \mathrm{mol} \times 10^{4}$ for male subjects and $0.3378 \pm 28.008 \mathrm{IU} / \mathrm{mol} \times 10^{4}$ for females respectively. In the North East zone, mean viral load value for male subjects was $0.3454 \pm 16.171 \mathrm{IU} / \mathrm{mol} \times 10^{4}$, while the mean value for female subjects was $0.0561 \pm 28.008 \mathrm{IU} / \mathrm{mol} \times 10^{4}$. Similarly, in the South South zone, the mean viral load value for male subjects was $0.7583 \pm 16.738 \mathrm{IU} / \mathrm{mol} \times 10^{4}$ while the mean value for female subjects was $0.7976 \pm 25.568 \mathrm{IU} / \mathrm{mol} \times 10^{4}$. The F Ratio and P-value were inestimable due to large variability.

\subsection{Lipid Profile of the Voluntary Blood Donors by Geopolitical Zone, Hepatitis B Status and Sex}

The lipid profile of the participants disaggregated by geopolitical zones, hepatitis B status and sex is shown in Table 3. The table shows that both HBsAg negative and HBsAg positive male and female participants in the three geopolitical zones had total cholesterol level within the normal reference range for the population. The pattern of plasma total cholesterol level across the geopolitical zones disaggregated by sex and HBsAg status is shown in Figure 1. The high density lipoprotein cholesterol level was reasonably normal for both HBsAg negative and HBsAg male and female participants in the three geoplitical zones. The pattern of distribution of high density lipoprotein cholesterol across the geopolitical zones disaggregated by sex and HBsAg status is shown in Figure 2. Also, the low density liporotein and triglycerides for both HBsAg negative and HBsAg positive male and female participants in the three geoplitical zones were also within normal reference limit [16]. The pattern of distribution of low density lipoprotein cholesterol and triglycerides concentrations across the geopolitical zones disaggregated by sex and HBsAg status are shown in Figure 3 and Figure 4 respectively. The pattern of distribution of the lipoproteins shows that total cholesterol and low density lipoprotein cholesterol were slightly higher in HBsAg positive male and female subjects in the North East while high density lipoprotein cholesterol concentrations were slightly higher in HBsAg positive male and female subjects in the South South and North East geopolitical zones. The pattern was normal in the North Central zone.

Table 2. Mean \pm SEM HBV viral load of volunteer donors by geopolitical zones.

\begin{tabular}{ccc}
\hline Geopolitical zones & Gender & HBV viral load (IU/mol) $\times 10^{4}$ \\
\hline \multirow{2}{*}{ North Central } & Female & $0.3378 \pm 28.008$ \\
& Male & $31.844 \pm 12.784$ \\
North East & Female & $0.0561 \pm 28.008$ \\
& Male & $0.3454 \pm 12.171$ \\
South South & Female & $0.7976 \pm 25.568$ \\
& Male & $0.7583 \pm 16.738$ \\
\hline
\end{tabular}


Table 3. Lipid profile parameters of volunteer blood donors by geo-political zone, hepatitis $B$ status and sex (Mean \pm SEM).

\begin{tabular}{|c|c|c|c|c|c|c|}
\hline $\begin{array}{c}\text { Geo-Political } \\
\text { Zone }\end{array}$ & $\begin{array}{l}\text { Hepatitis } \\
\text { B Status }\end{array}$ & Sex & $\begin{array}{c}\mathrm{T} \mathrm{CHOL} \\
(\mathrm{mmol} / \mathrm{L})\end{array}$ & $\begin{array}{c}\text { HDL-C } \\
(\mathrm{mmol} / \mathrm{L})\end{array}$ & $\begin{array}{c}\text { LDL-C } \\
(\mathrm{mmol} / \mathrm{L})\end{array}$ & $\begin{array}{c}\text { TRIG } \\
(\mathrm{mmol} / \mathrm{L})\end{array}$ \\
\hline \multirow{4}{*}{ North Central } & Negative & Female & $4.35 \pm 0.17$ & $1.17 \pm 0.08$ & $2.45 \pm 0.14$ & $0.99 \pm 0.09$ \\
\hline & Negative & Male & $4.71 \pm 0.10$ & $1.26 \pm 0.05$ & $2.76 \pm 0.08$ & $0.99 \pm 0.06$ \\
\hline & Positive & Female & $3.88 \pm 0.50$ & $1.18 \pm 0.22$ & $2.57 \pm 0.40$ & $0.96 \pm 0.26$ \\
\hline & Positive & Male & $4.29 \pm 0.23$ & $1.02 \pm 0.10$ & $2.68 \pm 0.18$ & $0.96 \pm 0.12$ \\
\hline \multirow{4}{*}{ North East } & Negative & Female & $4.73 \pm 0.17$ & $1.42 \pm 0.08$ & $2.60 \pm 0.14$ & $1.47 \pm 0.09$ \\
\hline & Negative & Male & $5.20 \pm 0.10$ & $1.42 \pm 0.05$ & $3.14 \pm 0.08$ & $1.40 \pm 0.06$ \\
\hline & Positive & Female & $5.56 \pm 0.50$ & $1.54 \pm 0.22$ & $3.74 \pm 0.40$ & $1.78 \pm 0.26$ \\
\hline & Positive & Male & $5.22 \pm 0.29$ & $1.57 \pm 0.13$ & $3.03 \pm 0.23$ & $1.55 \pm 0.15$ \\
\hline \multirow{4}{*}{ South-South } & Negative & Female & $4.49 \pm 0.17$ & $1.20 \pm 0.07$ & $2.76 \pm 0.13$ & $1.20 \pm 0.09$ \\
\hline & Negative & Male & $4.55 \pm 0.11$ & $1.15 \pm 0.05$ & $2.78 \pm 0.09$ & $1.29 \pm 0.06$ \\
\hline & Positive & Female & $4.42 \pm 0.45$ & $1.57 \pm 0.20$ & $2.59 \pm 0.36$ & $1.18 \pm 0.24$ \\
\hline & Positive & Male & $4.71 \pm 0.30$ & $1.71 \pm 0.13$ & $2.54 \pm 0.24$ & $1.75 \pm 0.16$ \\
\hline \multicolumn{2}{|c|}{ Test Statistic F-Ratio } & & 0.9067 & 0.7651 & 1.8231 & 1.0926 \\
\hline \multicolumn{2}{|c|}{$P$-value } & & $0.4045^{\mathrm{ns}}$ & $0.4658^{\text {ns }}$ & $0.1626^{\mathrm{ns}}$ & $0.3361^{\mathrm{ns}}$ \\
\hline
\end{tabular}

Keys: $\mathrm{TCHOL}=$ total cholesterol, HDL-C $=$ high density lipoprotein cholesterol, TRIG $=$ triglycerides, LDL-C $=$ low density lipoprotein cholesterol. Reference ranges: $\mathrm{Tchol}=$ up to $5.2 \mathrm{mmol} / \mathrm{L}, \mathrm{HDL}-\mathrm{C}$; Male $=$ $1.0-1.3 \mathrm{mmol} / \mathrm{L}$, female $=1.30-1.50 \mathrm{mmol} / \mathrm{L}, \mathrm{LDL}=1.96-3.40 \mathrm{mmol} / \mathrm{L}$, Trig. $\leq 2.3 \mathrm{mmol} / \mathrm{L}[16]$.

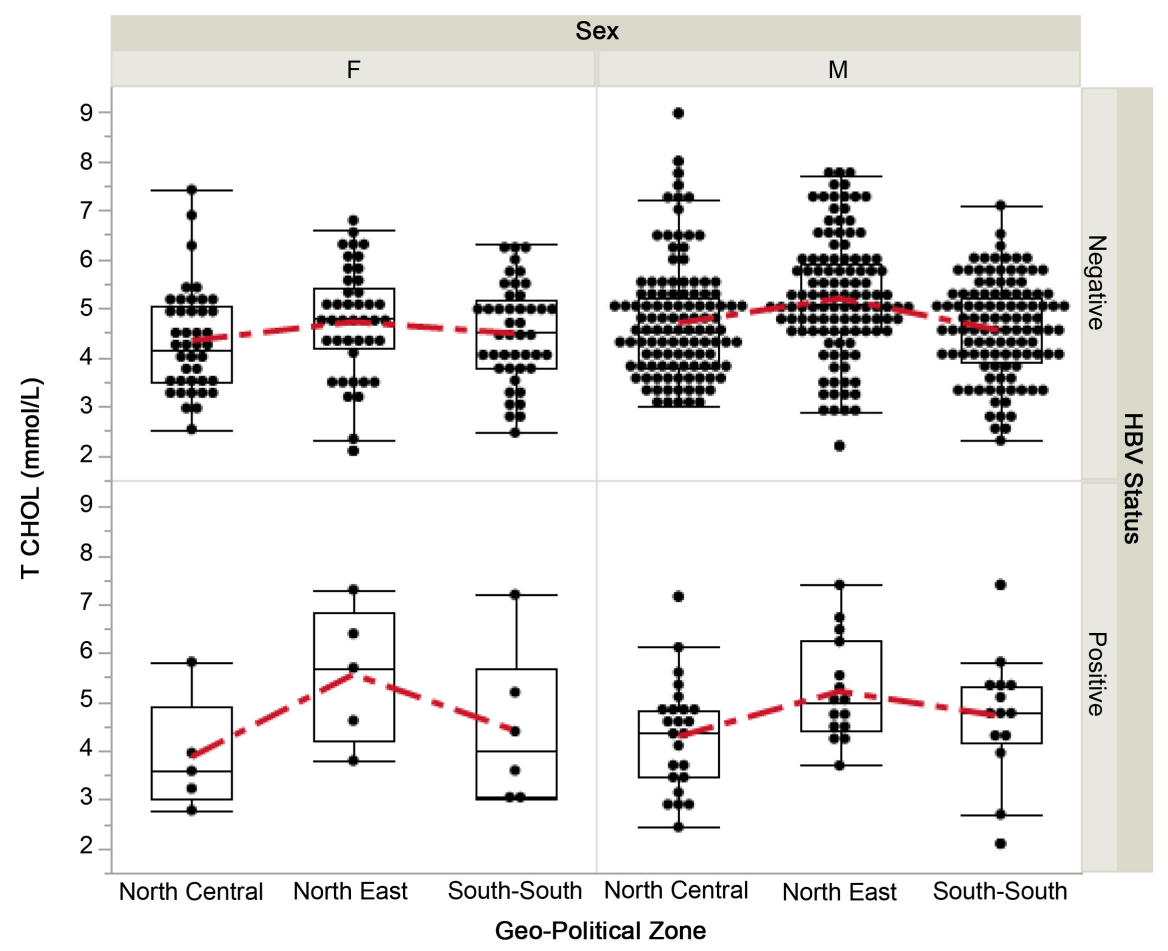

Figure 1. Box plot of total cholesterol by HBV status and sex of volunteer blood donors within geo-political zones. 


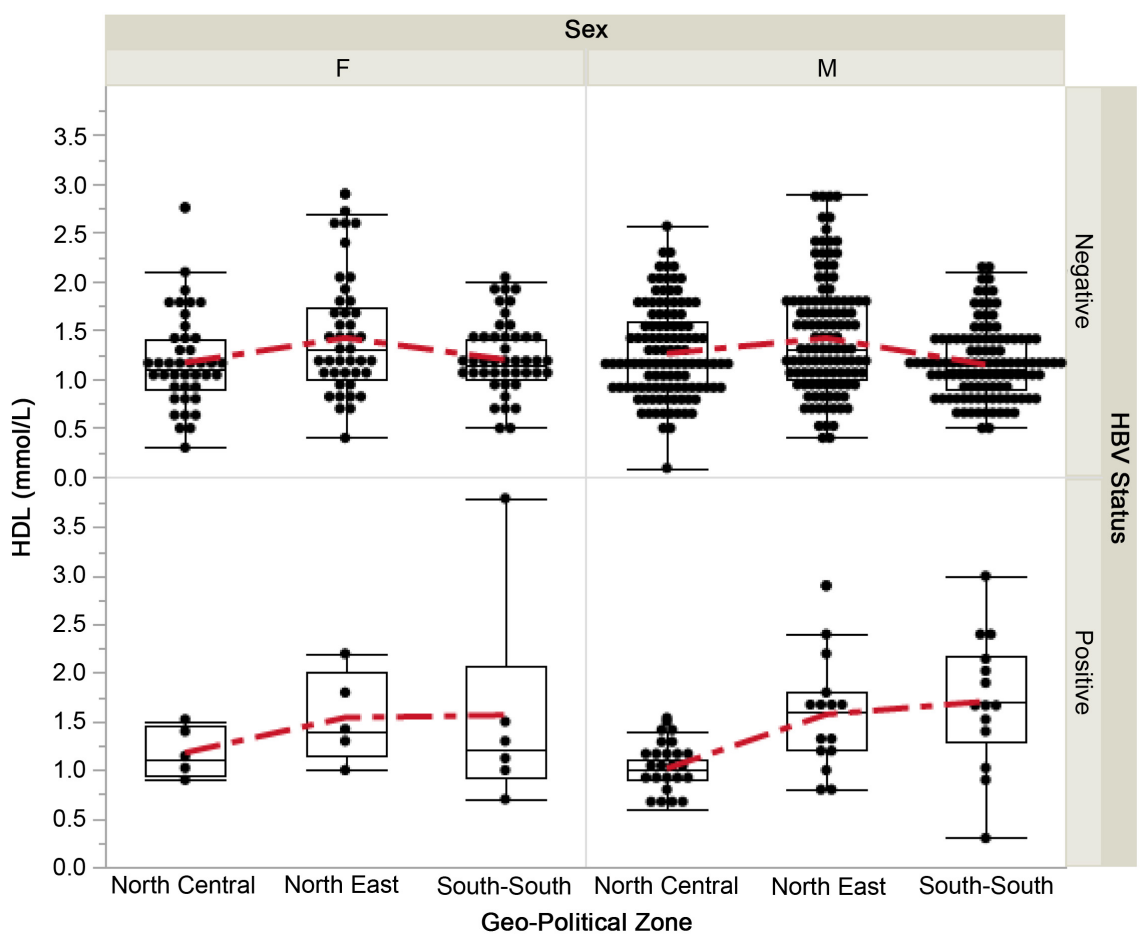

Figure 2. Box plot of high density lipoprotein by HBV status and sex of volunteer blood donors within geo-political zones.

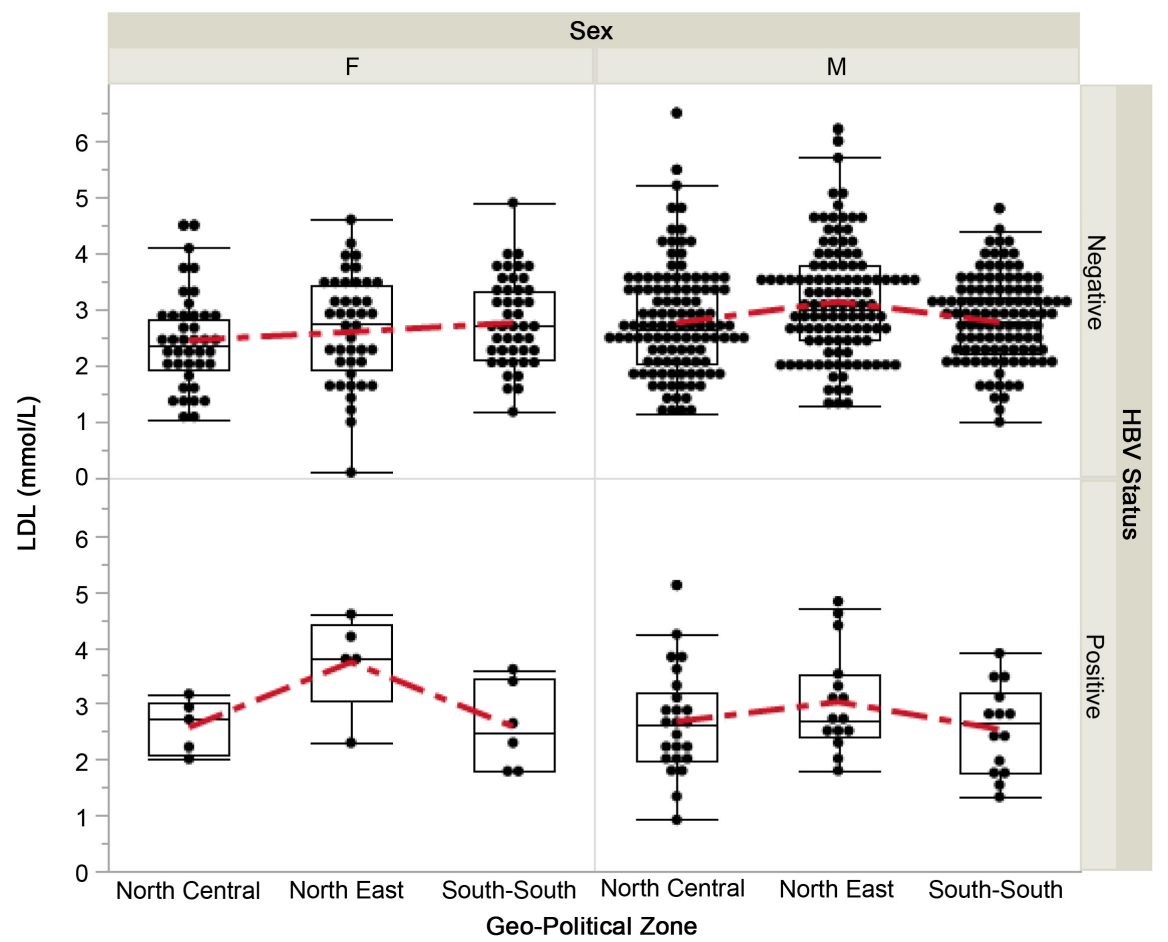

Figure 3. Box plot of low density lipoprotein by HBV status and sex of volunteer blood donors within geo-political zones.

\subsection{Atherogenic Profiles of the Voluntary Blood Donors}

The atherogenic profiles of the voluntary donors in the geopolitical zone was 


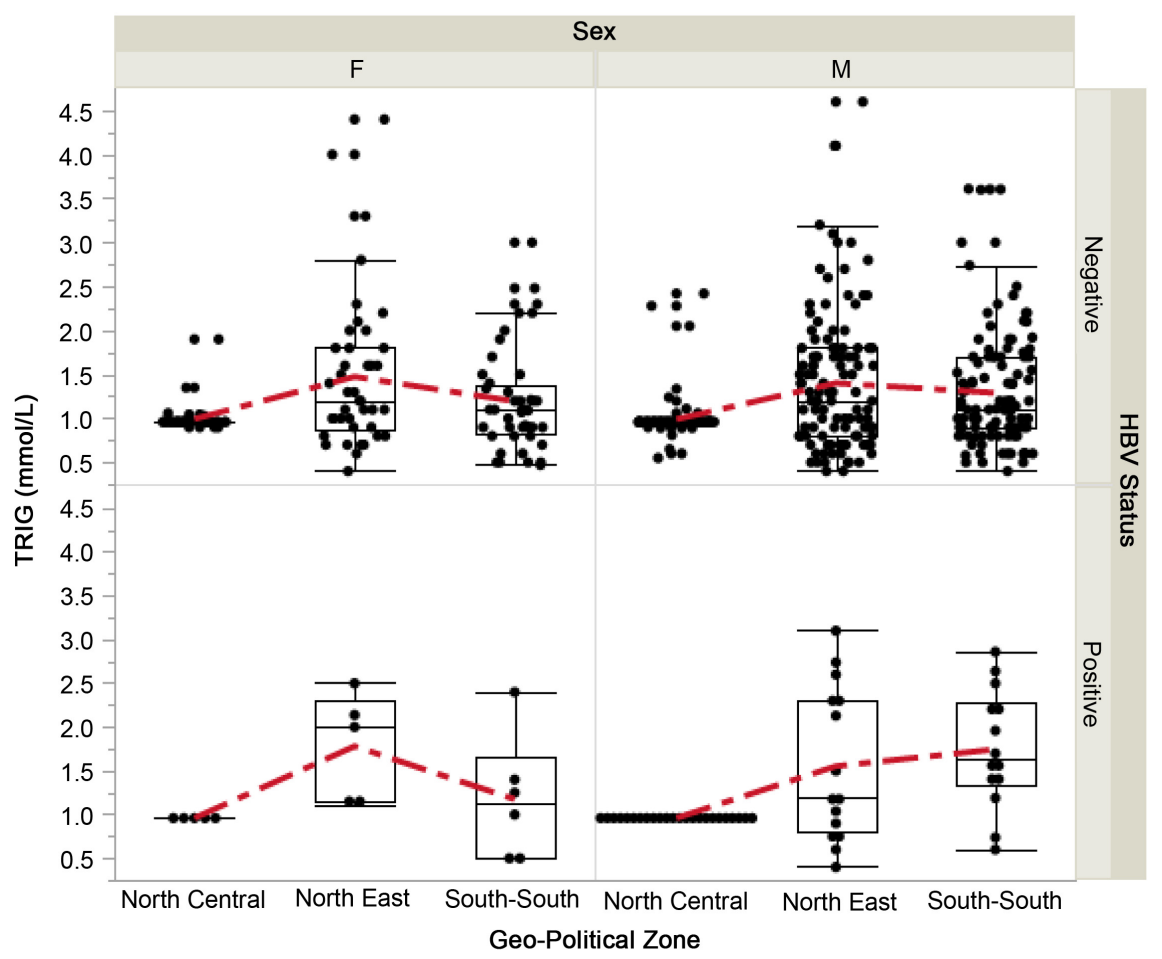

Figure 4. Box plot of triglycerides by HBV status and sex of volunteer blood donors within geo-political zones.

determined using Atherogenic Index of Plasma (AIP), Cardiac Risk Ratio-1 (CRR-1), Cardiac Risk Ratio-11 (CRR-11) and Atherogenic Coefficient (AC), and their values were compared with reference ranges for normal populations. The atherogenic profiles are shown in Table 4. The atherogenic profile of the blood donors in the three geopolitical zones was within acceptable reference range using AIP as the scoring index. The values in both the HBsAg positive and negative subjects were below $>0.1$. However, using CRR-1, most of the subjects from the three zones were at minimal risk of atherogenesis. CRR-2 did not indicate atherogenic risk for the subjects in the three zones but the computation of the AC shows that most of the HBsAg negative male and female subjects and HBsAg positive male in the North Central zone had AC value > 3.0. Only some HBsAg negative males in the North East zone had AC value > 3.0. In the South South zone, only the HBsAg negative male and female subjects had AC value > 3.0.

\section{Discussion}

Provision of safe blood is of paramount importance and it is the responsibility of the National Blood Transfusion Service and indeed all Units in both public and private health institutions to ensure that safe blood is made available for the purpose of transfusion to patients. Hepatitis B is a major health problem worldwide and is associated with life-threatening complications. As a result, it is recommended that each unit of blood has to be tested for hepatitis B infection [17]. 
Table 4. Atherogenic profiles of volunteer blood donors by geo-political zone, hepatitis B status and sex (Mean \pm SEM).

\begin{tabular}{cccccccc}
\hline $\begin{array}{c}\text { Geo-Political } \\
\text { Zone }\end{array}$ & $\begin{array}{c}\text { Hepatitis B } \\
\text { Status }\end{array}$ & Sex & $\mathrm{N}$ & AIP & CRR-I & CRR-II & AC \\
\hline \multirow{4}{*}{$\begin{array}{c}\text { North } \\
\text { Central }\end{array}$} & Negative & Female & 41 & $-0.040 \pm 0.036$ & $4.17 \pm 0.36$ & $2.37 \pm 0.25$ & $3.17 \pm 0.36$ \\
& Positive & Female & 5 & $-0.081 \pm 0.104$ & $3.51 \pm 1.04$ & $2.30 \pm 0.72$ & $2.51 \pm 1.04$ \\
& Positive & Male & 24 & $-0.014 \pm 0.047$ & $4.38 \pm 0.48$ & $2.74 \pm 0.33$ & $3.38 \pm 0.48$ \\
& Negative & Female & 42 & $-0.007 \pm 0.036$ & $3.76 \pm 0.36$ & $2.20 \pm 0.25$ & $2.76 \pm 0.36$ \\
North & Negative & Male & 114 & $-0.029 \pm 0.022$ & $4.15 \pm 0.22$ & $2.63 \pm 0.15$ & $3.15 \pm 0.22$ \\
& Positive & Female & 5 & $0.057 \pm 0.104$ & $3.70 \pm 1.04$ & $2.51 \pm 0.72$ & $2.70 \pm 1.04$ \\
& Positive & Male & 15 & $-0.052 \pm 0.060$ & $3.66 \pm 0.60$ & $2.23 \pm 0.42$ & $2.66 \pm 0.60$ \\
& Negative & Female & 44 & $-0.026 \pm 0.035$ & $4.05 \pm 0.35$ & $2.54 \pm 0.24$ & $3.05 \pm 0.35$ \\
& Negative & Male & 109 & $0.027 \pm 0.022$ & $4.23 \pm 0.22$ & $2.61 \pm 0.15$ & $3.23 \pm 0.22$ \\
South-South & Positive & Female & 6 & $-0.123 \pm 0.095$ & $3.24 \pm 0.95$ & $1.95 \pm 0.66$ & $2.24 \pm 0.95$ \\
& Positive & Male & 14 & $0.021 \pm 0.062$ & $3.15 \pm 0.06$ & $1.78 \pm 0.43$ & $2.15 \pm 0.62$ \\
& Test Statistic $F-$ Ratio & & 0.7296 & 0.1982 & 0.2571 & 0.1982 \\
& P-value & & & $0.4826^{\mathrm{ns}}$ & $0.8202^{\mathrm{ns}}$ & $0.7734^{\mathrm{ns}}$ & $0.8202^{\mathrm{ns}}$ \\
\hline
\end{tabular}

Significance Level: $\mathrm{ns}=$ Not significant $(\mathrm{p}>0.05)$. Abnormal values for cardiovascular risk AIP: $>0.1$, AC $>$ 3.0, CRR-I > 3.5 in males and $>3.0$ in females, and CRR-II $>3.3$.

In our study among 532 blood donors screened, the overall seroprevalence of HBsAg positive from the three geopolitical zones was observed to be $12.92 \%$ (total 69 cases) which is quite high when compared with similar study conducted by Remya et al. [18] and Shah et al. [19] in India. Studies in the seventies among apparently healthy Iraqi population showed that the prevalence of HBsAg in blood donors and military personnel blood donors was 3.6\% and in normal population it was $3.3 \%$ while in eighties it was $4.3 \%$ in normal population and $4.1 \%$ in blood donors [20]. Comparing these values to the data obtained from this study, it is obvious that much needed to be done to avert complications that could arise from patients receiving "screened blood" from our hospitals. In our study, most of the HBsAg positive donors were relatively young within the age range of $32-41$ years. This age range is comparable with that reported in the studies conducted by Baba et al. in 2000 [21], Tiruneh in 2008 [22], Quadri et al. in 2013, [23] and Remya et al. [18]. Our study also shows that the age range was lower in the female subjects when compared to the male counterparts.

It is known that maintained high levels of HBV DNA are associated with progressive liver disease. Serum DNA levels are a prognostic factor and contribute to define the phase of chronic hepatitis B infection, the treatment indication, and allow an assessment of the efficacy of antiviral therapy. High levels of HBV DNA are an independent risk factor for cirrhosis [24]. Patients with low HBV-DNA levels, between 300 and $10^{4}$ copies $/ \mathrm{mL}$, have, although a very low one, a risk of progression to cirrhosis and hepatocellular carcinoma (HCC) [25]. The DNA 
levels obtained in this study for HBsAg positive volunteer blood donors in the three geopolitical zones ranged between $561-318,440$ copies $/ \mathrm{mL}$. These DNA values in these asymptomatic carriers are high enough to trigger a progression in Hepatitis B infection among these subjects since multi-factorial processes including interaction between host and environmental factors has been shown to greatly enhance manifestation of hepatis B infection [26]. The HBV DNA were higher in the male than in the female HBsAg positive subjects in both the North central and North East zones except in the South South zone where it was found to be higher in the female HBsAg positive subjects. The highest HBV DNA value was recorded in the HBsAg positive males in the North Central zone.

Data from the South Korean nationwide health and nutrition examination showed that HBV carriers have lower LDL cholesterol and triglyceride levels compared with control subjects. HBsAg carriers also showed a tendency for higher HDL cholesterol levels despite its relative lack of statistical significance [27]. In our present study, no significant variation was observed in the levels of LDL cholesterol, and triglycerides between the HBsAg negative and HBsAg positive carriers instead LDL cholesterol and triglycerides were found to be insignificantly increased in the North East HBsAg positive subjects. Owing to absence of hypertriglyceridaemia and low HDL-cholesterolaemia in these subjects, the prevalence of metabolic syndrome may be significantly lower in HBsAg carriers in these geopolitical zones. Our study also indicated that asymptomatic HBV infection may be associated with low risk of dyslipidaemia aside from low lipid levels, which are associated with decreased lipid metabolism in liver diseases. This finding corroborates with the report of Koo and Moon [28]. It has also been reported that in advanced disease, HDL cholesterol levels are also significantly decreased as disease severity increases [29].

Abnormal lipid profile has been recognized as one of the most influential risk factors for the development of coronary artery disease (CAD) by the INTER HEART study [30]. Low HDL-C concentrations, high triglycerides and increased levels of LDL-C are known to aggravate the incidence of coronary artery disease [31] [32]. It was observed in our study, that the levels of total cholesterol, high density lipoprotein cholesterol, low density lipoprotein cholesterol and triglycerides were higher in both HBsAg negative and HBsAg positive carrier blood donors in the North East geopolitical zone than was seen in the North Central and South South geopolitical zones. However, high density lipoprotein cholesterol level was observed to be higher in HBsAg positive male and female subjects in the North East and South South geopolitical zones indicating that asymptomatic HBV infection may be associated with low risk of dyslipidaemia aside from low lipid levels.

Similarly, the different combinations of lipid profile parameters are considered to have optimal predictive capacity of the profile. Moreover, Atherogenic Index of Plasma (AIP), Cardiac Risk Ratio 1 and 2 (CRR-1 and CRR-2) and Atherogenic coefficient (AC) are the ratios shown to have high predictive values for cardiovascular risk assessment [33]. High density lipoprotein cholesterol has 
been reported to have a protective effect against cardiovascular diseases [34]. The comparison of the atherogenic indexes across the three geopolitical zones shows that HBsAg negative male and female subjects in the North central and South South and only males in the North East zones have moderately increased atherogenic coefficient value above 3.0. The reason behind this contracdictory obervations in this study cannot be easily offered but it is, however, a pointer to the fact that subsequent studies to elucidate the mechanism of lipid metabolism in HBV infection in these populations in Nigeria are required although similar finding has been reported by Koo and Moon [28].

There are several limitations to this study. Firstly, since this is a cross-sectional study, a causal relationship could not be proven. We could not show the mechanism underlying not only the association between lipid profile and HBsAg status but also the discrepancy in the lipid levels obtained in this study. Secondly, the questionnaires were self-reported, and may have been subjected to recall bias. Our inability to identify the occupation of the participants and obtain data on certain risk factors for lipid profile related abnormality such as diet and physical inactivity from the subjects could have impacted on the results obtained in this study. Lastly, our findings may be limited to blood donor populations who may have chosen to live apparently low risk lifestyle.

\section{Conclusion}

Considering the sample size used in this study, it could be postulated that the seroprevalence rate of HBsAg in our study is moderately high. Therefore, a more stringent comprehensive screening of blood donors is highly recommended before blood transfusion service should be performed. With the advent of nucleic acid amplification and molecular assay designed for the quantification of HBV DNA, it may be possible to decrease the risk of HBV transmission to a major extent although it is not cost effective. Since our study revealed a high seroprevalence between the age group of 32 - 41, better education of donors and improved prophylactic measures at public levels should always be done to ensure safe blood donation. Proper predonation counseling and donor self-exclusion are also necessary. The study also revealed that the presence of HBsAg in the population could occultly complicate the cardiovascular profile of individuals in these zones, thus, strengthening the recommendation of elaborate HBV screening and elucidation of its impact on the cardiovascular profile of Nigerians across the six geopolitical zones of Nigeria.

\section{Acknowledgements}

The authors are grateful to the voluntary blood donors who agreed to take part in this study.

\section{Conflicts of Interest}

There is no conflict of interest. 


\section{Funding}

The author(s) received no funding support for this study, authorship, and/or publication of this article.

\section{References}

[1] World Health Organization (2018) Hepatitis B: Fact Sheet. http://www.who.int/news-room/fact-sheets/detail/hepatitis-b

[2] World Health Organization (2015) Guideline for the Prevention, Care Aid Treatment of Persons with Chronic Hepatitis B Infection. Geneva.

[3] Souza, B.F.D., Drexter, J.F., Santos de Lima, R., Veiga De Rosario, M.O.H. and Netto, E.M. (2014) Theories about Evolutionary Origins of Human Hepatitis B Virus in Primates and Humans. Brazilian Journal of Infectious Diseases, 18, 535-543. https://doi.org/10.1016/j.bjid.2013.12.006

[4] Dufour, D.R. (2015) Liver Disease. In: Tietz Fundamentals of Clinical Chemistry and Molecular Diagnostics, 7th Edition, Saunders Elsevier, Missouri, 1777-1847.

[5] Pan, C.Q. and Zhang, J.X. (2005) Natural History and Clinical Consequences of Hepatitis B Virus Infection. International Journal of Medical Sciences, 2, 36-40. https://doi.org/10.7150/ijms.2.36

[6] Burtis, C.A. and Bruns, D.E. (2015) Tietz Fundamentals of Clinical Chemistry and Molecular Diagnostics. 7th Edition, Elsevier Missouri, Saunders, 364-370.

[7] Maini, M.K., Bonic lee, C.K., Lamubia, J.R., Reighat, S., Ogg, G.S., King, A.S., Herber, G.J., Gilson, R., Alisa, A., Williams, R., Vergani, D., Naoumov, N., Ferraric, A. and Bertoletti, A. (2000) The Role of Virus-Specific Cd8t Cells in Liner Damage and Viral Control during Persistent Hepatitis B Virus Infection. The Journal of Experimental Medicine, 191, 1269-1292. https://doi.org/10.1084/jem.191.8.1269

[8] Charan, J. and Biswas, T. (2013) How to Calculate Sample Size for Different Study Designs in Medical Research. Indian Journal of Psychology and Medicine, 35, 121-126. https://doi.org/10.4103/0253-7176.116232

[9] Bio-Rad (2013) Monolisa HBsAg Ultra Kit for the Detection of the Surface Antigen of the Hepatitis B Virus in Human Serum or Plasma by Enzyme Immunoassay. Bio-Rad 92430 Marnes-la-Coquette-France.

[10] Roche (2012) COBAS Ampliprep/COBAS Taqman HBV Test, Version 2.0 Roche Molecular Systems Inc. Roche Diagnostics GmbH, Sandhofer Str. 11668305 Mannheim, Germany.

[11] Friedewald, W.T., Levy, R.I. and Fredrickson, D.S. (1972) Estimation of the Concentration of Low Density Lipoprotein Cholesterol in Plasma without Use of Preparative Ultra Centrifuge. Clinical Chemistry, 18, 499-502. https://doi.org/10.1093/clinchem/18.6.499

[12] Dobiasova, M. (2004) Atherogenic Index of Plasma [Log(Triglycerides/HDLCholesterol)]: Theoretical and Practical Implications. Clinical Chemistry, 50, 1113-1115. https://doi.org/10.1373/clinchem.2004.033175

[13] Stampfer, M.J., Sacks, F.M., Salvini, S., Willett, W.C. and Hennekens, C.H. (1991) A Prospective Study of Cholesterol, Apolipoproteins, and the Risk of Myocardial Infarction. New England Journal of Medicine, 325, 373-381. https://doi.org/10.1056/NEJM199108083250601

[14] Ridker, P.M., Stampfer, M.J. and Rifai, N. (2001) Novel Risk Factors for Systemic Atherosclerosis: A Comparison of C-Reactive Protein, Fibrinogen, Homocysteine, 
Lipoprotein(a), and Standard Cholesterol Screening as Predictors of Peripheral Arterial Disease. Journal of American Medical Association, 285, 2481-2485. https://doi.org/10.1001/jama.285.19.2481

[15] Brehm, A., Pfeiler, G., Pacini, G., Vierhapper, H. and Roden, M. (2004) Relationship between Serum Lipoprotein Ratios and Insulin Resistance in Obesity. Clinical Chemistry, 50, 2316-2322. https://doi.org/10.1373/clinchem.2004.037556

[16] McMillin, G.A., Burtis, C.A. and Bruns, D.E. (2015) Reference Information for the Clinical Laboratory. In: Tietz Fundamentals of Clinical Chemistry and Molecular Diagnostics, 7th Edition, Saunders, Missouri, 951-992.

[17] Jadeja, P., Kaur, A. and Shekha, H. (2014) Trend in Seroprevalence of Hepatitis b Virus Infection among Blood Donors at a Tertiary Care Centre of Rajasthan, India. National Journal Medical Research, 4, 205-207. https://pdfs.semantischolar.org/09da/26c5349febe973e53f5513c15223ca64275c.pdf

[18] Remya, R. (2014) Serosurveillance of HBsAG Positive Patients in Voluntary Blood Donors. International Journal of Innovative Research in Science, Engineering and Technology, 3, 17165-1169. https://doi.org/10.15680/IJIRSET.2014.0311011

[19] Shah, N., Shah, J.M., Patel, K., Shah, C.K. and Sha, N.R. (2013) Prevalence of HBV, HCV, HIV and Syphilis among Blood Donors at a Tertiary Care Teaching Hospital in Western India. Gujarat Medical Journal, 68, 1-5.

[20] Atallah, M.T. (1987) Clinical and Laboratory Assessment of Hepatitis B Surface Antigen Healthy Carriers [Thesis]. University of Baghdad: College of Medicine.

[21] Baba, M.M., Hassan, A.W. and Gashau, W. (2009) Prevalence of Hepatitis B Antigenaemia and Human Immunodeficiency Virus in Blood Donors in Maidugiri, Nigeria. Nigerian Journal Medicine, 9, 10-12.

[22] Tiruneh, M. (2008) Sero Prevalence of Sexually Transmitted Infections among Antenatal Clinic Attendees in Gonder Health Centre, Northwest Ethiopia. Ethiopian Medical Journal, 46, 359-366.

[23] Quadri, S.A., Dadapeer, H.J., Arifulla, K.M. and Khan, N. (2013) Prevalence of Hepatitis B Surface Antigen in Hospital Based Population in Bijapur, Karnataka. AI Ameen Journal of Medical Science, 6, 180-182.

[24] Fattovich, G., Olivari, N., Pasino, M., D’Onofrio, M., Martone, E. and Donato, F. (2008) Long-Term Outcome of Chronic Hepatitis B in Caucasian Patients: Mortality after 25 Years. Gut, 57, 84-90. https://doi.org/10.1136/gut.2007.128496

[25] Shao, J., Wei, L., Wang, H., Sun, Y., Zhang, L.F., Li, J. and Dong, J.Q. (2007) Relationship between Hepatitis B Virus DNA Levels and Liver Histology in Patients with Chronic Hepatitis B. World Journal Gastroenterology, 13, 2104-2107.

http://www.wjgnet.com/1007-9327/13/2104.asp

https://doi.org/10.3748/wjg.v13.i14.2104

[26] Marugán, R.B. and Garzón, S.G. (2009) DNA-Guided Hepatitis B Treatment, Viral Load Is Essential, But Not Sufficient. World Journal Gastroenterology, 15, 423-430. http://www.wjgnet.com https://doi.org/10.3748/wjg.15.423

[27] Jan, C.F., Chen, C.J., Chiu, Y.H., Chen, L.S, Wu, H.M. and Huang, C.C. (2006) A Population-Based Study Investigating the Association between Metabolic Syndrome and Hepatitis B/C Infection (Keelung Community-Based Integrated Screening Study No. 10). International Journal of Obstetrics (London), 30, 794-799. https://doi.org/10.1038/sj.ijo.0803204

[28] Koo, B.K. and Moon, M.K. (2016) Serum Lipid Level in HBsAg Carriers without a 
History of Hepatitis Based on Nationwide Health and Nutrition Examination Datasets. Journal of Lipid and Atherosclerosis, 5, 133-143.

https://doi.org/10.12997/jla.2016.5.2.133

[29] Ghadir, M.R., Riahin, A.A., Havaspour, A., Nooranipour, M. and Habibinejad, A.A. (2010) The Relationship between Lipid Profile and Severity of Liver Damage in Cirrhotic Patients. Hepatitis Monthly, 10, 285-288.

[30] Enas, E.A. and Senthikumar, A. (2001) Coronary Artery Disease in Asian Indians: An Update and Review. The Internet Journal of Cardiology, 1, 1-22. https://doi.org/10.5580/5ba

[31] Yusuf, S., Hawken, S., Ounpuu, S., Dans, T., Avezum, A., Lanas, F., Mc Queen, M., Budaji, A., Pais, P., Varigos, J. and Lisheng, L. (2004) Effect of Potentially Modifiable Risk Factors Associated with Myocardial Infarction in 52 Countries (The Inter Heart Study): Case-Control Study. The Lancet, 364, 937-952.

https://doi.org/10.1016/S0140-6736(04)17018-9

[32] Daphna, W.V. and Pajukanta, P. (2010) Genetic Causes of High and Low Serum HDL Cholesterol. Journal of Lipid Research, 51, 2032-2057.

https://doi.org/10.1194/jlr.R004739

[33] Bharatwaj, R.S., Vijaya, K. and Rajaram, P. (2012) A Descriptive Study of Knowledge, Attitude and Practice with Regard to Voluntary Blood Donation among India. Journal of Clinical Diagnostics and Research, 6, 602-604.

[34] Gordon, T., Castelli, W.P., Hjortland, M.C., Kannel, W.B. and Dawber, T.R. (1997) High Density Lipoprotein as a Protective Factor against Coronary Heart Disease: The Framingham Study. American Journal of Medicine, 62, 707-714. https://doi.org/10.1016/0002-9343(77)90874-9 